ARTICLE

Received 9 Jan 2013 | Accepted 18 Apr 2013 | Published 14 May 2013

DOI: $10.1038 /$ ncomms2891

OPEN

\title{
Selective isolation of gold facilitated by second-sphere coordination with $\alpha$-cyclodextrin
}

Zhichang Liu ${ }^{1}$, Marco Frasconi ${ }^{1}$, Juying Lei ${ }^{1}$, Zachary J. Brown ${ }^{1}$, Zhixue Zhu1 ${ }^{1}$ Dennis Cao ${ }^{1}$, Julien lehl ${ }^{1}$, Guoliang Liu', Albert C. Fahrenbach1, Youssry Y. Botros 2,3,4, Omar K. Farha1, Joseph T. Hupp', Chad A. Mirkin ${ }^{1} \&$ J. Fraser Stoddart ${ }^{1}$

Gold recovery using environmentally benign chemistry is imperative from an environmental perspective. Here we report the spontaneous assembly of a one-dimensional supramolecular complex with an extended $\left\{\left[\mathrm{K}\left(\mathrm{OH}_{2}\right)_{6}\right]\left[\mathrm{AuBr}_{4}\right] \subset(\alpha \text {-cyclodextrin })_{2}\right\}_{n}$ chain superstructure formed during the rapid co-precipitation of $\alpha$-cyclodextrin and $\mathrm{KAuBr}_{4}$ in water. This phase change is selective for this gold salt, even in the presence of other square-planar palladium and platinum complexes. From single-crystal $X$-ray analyses of six inclusion complexes between $\alpha$-, $\beta$ - and $\gamma$-cyclodextrins with $\mathrm{KAuBr}_{4}$ and $\mathrm{KAuCl}_{4}$, we hypothesize that a perfect match in molecular recognition between $\alpha$-cyclodextrin and $\left[\mathrm{AuBr}_{4}\right]^{-}$leads to a near-axial orientation of the ion with respect to the $\alpha$-cyclodextrin channel, which facilitates a highly

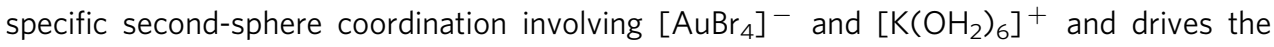
co-precipitation of the 1:2 adduct. This discovery heralds a green host-guest procedure for gold recovery from gold-bearing raw materials making use of $\alpha$-cyclodextrin-an inexpensive and environmentally benign carbohydrate.

\footnotetext{
${ }^{1}$ Department of Chemistry, Northwestern University, 2145 Sheridan Road, Evanston, Illinois 60208-3113, USA. ${ }^{2}$ Department of Materials Science and Engineering, Northwestern University, 2145 Sheridan Road, Evanston, Illinois 60208-3113, USA. ${ }^{3}$ Intel Labs, Building RNB-6-61, 2200 Mission College Boulevard, Santa Clara, California 95054-1549, USA. ${ }^{4}$ National Center for Nanotechnology Research, King Abdulaziz City for Science and Technology (KACST), P.O. Box 6086, Riyadh 11442, Saudi Arabia. Correspondence and requests for materials should be addressed to J.F.S.

(email: stoddart@northwestern.edu).
} 
T he interaction of human beings with gold is an activity that has been ongoing since ancient times as a result of this precious metal's unique physical and chemical properties. As the price of gold has skyrocketed during the past decade, a significant economic incentive exists for its recovery ${ }^{1}$, not only from ores, but also from the waste products of consumer electronics. In addition to this incentive, developing green methodologies for gold extraction and recovery is important from an environmental perspective. The most commonly used process for gold recovery involves the use of highly poisonous inorganic cyanides to convert $\operatorname{gold}(0)$ into a water-soluble $\mathrm{Au}(\mathrm{CN})_{2}^{-}$coordination complex by a process known as leaching, followed by its isolation using cementation, absorption or solvent extraction as typical methods ${ }^{2}$. As application of cyanide leaching to gold recovery has often resulted ${ }^{1}$ in contamination of the environment from accidental leakages and exposures, developing processes for gold recovery using environmentally benign chemistry is not only important from a green chemistry point of view, but it may also lead to procedures which will become more economically viable than the current ones.

The use of host-guest chemistry ${ }^{3}$, which has the advantage of requiring only mild conditions in order to afford complexes with well-defined and specific non-covalent bonding interactions driving their recognition processes, has not been well investigated as an isolation procedure for gold. Some of the most common hosts are the cyclodextrins (CDs), which are cyclic oligosaccharides with hydrophobic cavities that can house nonpolar guests. They often lead to the formation of one-dimensional supramolecular inclusion polymers ${ }^{4-9}$, typically pseudopolyrotaxanes, with a wide variety of organic ${ }^{10-12}$, organometallic ${ }^{13-19}$ and inorganic ${ }^{20-23}$ guests. The structural compatibility between the CDs and the guests is the key preorganization parameter to consider when designing $\mathrm{CD}$ inclusion complexes, while hydrophobic interactions ${ }^{4}$, in addition to second-sphere coordination $^{25-27}$, provide major contributions to the stabilities of these complexes. Although numerous single-crystal superstructures $^{4-7,20}$ of $\mathrm{CD}$ inclusion complexes exist in the literature, the formation of $\mathrm{CD}$ host-guest complexes with gold salts as guests has not been explored to our knowledge.

Herein, we report the unprecedented and rapid formation of a well-defined one-dimensional single-crystalline material, which features a high-aspect-ratio and coaxial core-shell superstructure. It relies on the self-assembly of $\mathrm{KAuBr}_{4}$ and $\alpha$-CD in aqueous solution to form (Fig. 1), as a co-precipitate, a 1:2 complex, $\mathrm{KAuBr}_{4} \bullet(\alpha-\mathrm{CD})_{2} \quad(\boldsymbol{\alpha} \bullet \mathrm{Br}), \quad$ with an extended $\left\{\left[\mathrm{K}_{\left.\left(\mathrm{OH}_{2}\right)_{6}\right]}\right.\right.$
$\left.\left[\mathrm{AuBr}_{4}\right] \subset(\alpha-\mathrm{CD})_{2}\right\}_{\mathrm{n}}$ chain superstructure. The formation of this hybrid material is confirmed by scanning (SEM), transmission (TEM) electron and atomic force (AFM) microscopies, as well as by electron diffraction, while the superstructure has been characterized by single-crystal and powder X-ray diffraction (XRD). The rapid co-precipitation of the $\alpha \bullet \mathbf{B r}$ complex between $\mathrm{KAuBr}_{4}$ and $\alpha-\mathrm{CD}$ is highly specific: it does not materialize, for example, even if $\mathrm{KAuCl}_{4}$ is employed as an alternative gold salt, or if $\beta$ - or $\gamma$-CD is substituted for $\alpha$-CD. We have also discovered that the co-precipitation of $\alpha \cdot \mathbf{B r}$ is selective for gold, even in the presence of other square-planar noble metal complexes, such as those involving palladium and platinum. A laboratory scale gold recovery process has also been developed, based on the selective co-precipitation of $\boldsymbol{\alpha} \bullet \mathbf{B r}$, by employing gold-bearing scraps as raw materials. From a detailed analysis of the single-crystal X-ray superstructures of an extensive range of inclusion complexes between $\alpha$-, $\beta$ - or $\gamma$-CDs with $\mathrm{KAuX}_{4}(\mathrm{X}=\mathrm{Cl}, \mathrm{Br})$, we hypothesize that the perfect molecular recognition between the $\alpha$-CD ring and the square-planar $\left[\mathrm{AuBr}_{4}\right]^{-}$anion, which leads to an axial orientation of the anion with respect to the channel of $\alpha$ $\mathrm{CD}$ rings, facilitates a highly specific second-sphere coordination involving, not only the $\left[\mathrm{AuBr}_{4}\right]^{-}$anion, but also the $\left[\mathrm{K}\left(\mathrm{OH}_{2}\right)_{6}\right]^{+}$cation, driving the formation and rapid selective co-precipitation of the $\boldsymbol{\alpha} \bullet \mathbf{B r}$ complex. This bulk process, which is reminiscent ${ }^{25}$ of the second-sphere coordination of transitionmetal ammines with [18]crown-6, wherein $\left[\mathrm{Cu}\left(\mathrm{NH}_{3}\right)_{4}\left(\mathrm{H}_{2} \mathrm{O}\right)\right]$ $\left[\mathrm{PF}_{6}\right]_{2}$ can be separated ${ }^{28}$ as a crystalline co-precipitate from $\left[\mathrm{Co}\left(\mathrm{NH}_{3}\right)_{6}\right]\left[\mathrm{PF}_{6}\right]_{3}$ in aqueous solution, represents a promising strategy that relies on second-sphere coordination, providing a very attractive host-guest procedure for gold recovery in the form of $\mathrm{KAuBr}_{4}$, starting from gold-bearing raw materials and making use of $\alpha-C D$, an inexpensive and environmentally benign carbohydrate, as the host.

\section{Results}

Formation and characterization of $\alpha \bullet \mathrm{Br}$. Minimal variations in the building blocks employed in molecular self-assembly processes can lead to totally different superstructures and physical properties ${ }^{29-33}$, reflecting the subtle interplay between weak non-covalent bonding forces, particularly hydrogen bonding ${ }^{34-37}$ in the case of CDs.

Upon mixing any particular aqueous solution $(20 \mathrm{mM}, 1 \mathrm{ml})$ of $\mathrm{KAuX}_{4}$ with any chosen aqueous solution $(26.7 \mathrm{mM}, 1.5 \mathrm{ml})$ of $\alpha-, \beta-$, or $\gamma$-CDs at room temperature, a shiny pale brown suspension forms exclusively within a few minutes (Fig. 2 and

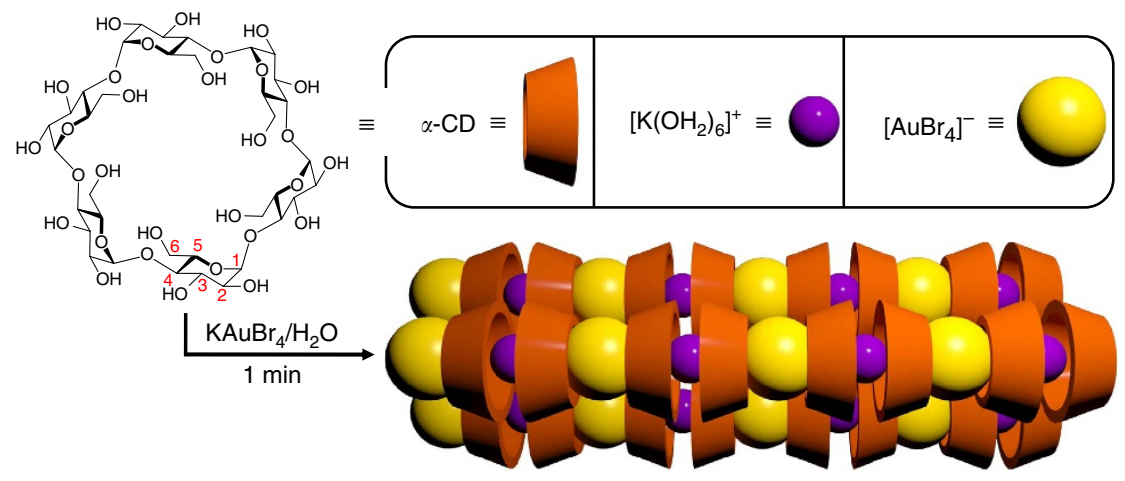

Figure 1 | Schematic representation of the spontaneous self-assembly of $\alpha \bullet B r$. Upon mixing $\mathrm{KAuBr}_{4}$ and $\alpha-\mathrm{CD}$ in water, a hydrogen-bonded linear superstructure forms spontaneously in $<1 \mathrm{~min}$. The cavities of the $\alpha$-CDs oriented head-to-head, tail-to-tail form a continuous channel, which is filled

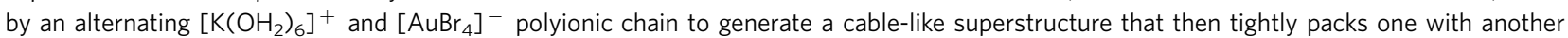
(Supplementary Fig. S1) leading to crystals observable to the naked eye. 


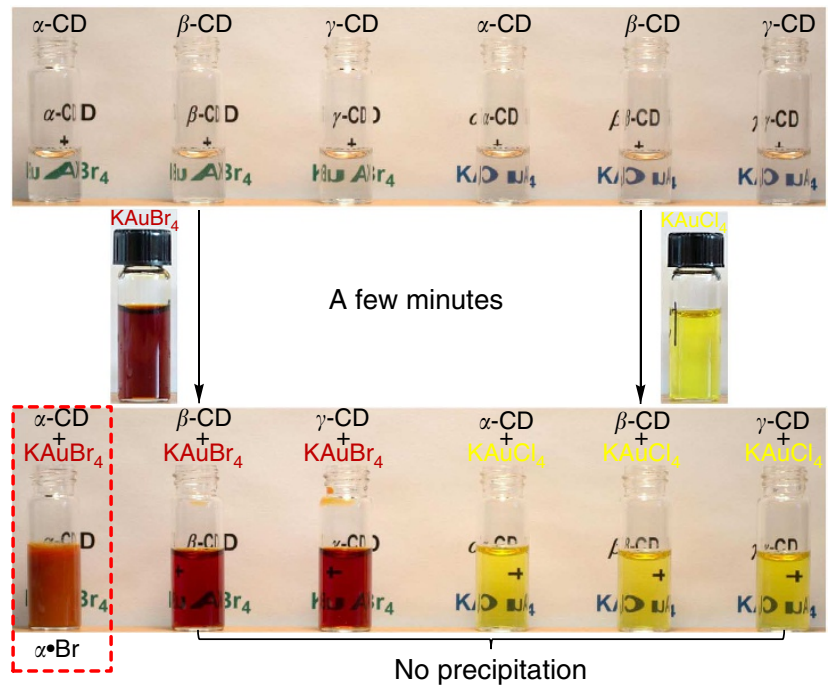

Figure 2 | Formation and co-precipitation of $\alpha \bullet B r$ from $\mathrm{KAuBr}_{4}$ and $\alpha-\mathrm{CD}$. When an aqueous solution $(20 \mathrm{mM}, 1 \mathrm{ml})$ of $\mathrm{KAuX}_{4}(\mathrm{X}=\mathrm{Cl}$ or $\mathrm{Br})$ is added to an aqueous solution $(26.7 \mathrm{mM}, 1.5 \mathrm{ml})$ of $\alpha-, \beta-$, or $\gamma-C D$, a shiny pale brown suspension forms exclusively from the combination of $\mathrm{KAuBr}_{4}$ and $\alpha-\mathrm{CD}$ within 1-2 min (See Supplementary Movie 1).

Supplementary Movie 1) when $\mathrm{KAuBr}_{4}$ and $\alpha$-CD form the 1:2 adduct, $\alpha \bullet B r$. Centrifugal filtration and drying under vacuum of the suspension permits the isolation of the $\alpha \bullet \mathbf{B r}$ complex in bulk as a pale brown powder.

SEM of an air-dried aqueous suspension of the $\alpha \bullet B r$ complex reveals (Fig. 3a) the formation of long, needle-like crystals with extremely high aspect ratios. Examination of a suspension of these nanostructures by TEM reveals (Fig. 3b) that they have diameters of a few hundred nanometres and lengths on the order of micrometres. The nanostructures were stabilized under cryoTEM conditions and then subjected to selected area electron diffraction (SAED). SAED patterns of the assembly of the $\boldsymbol{\alpha \bullet B r}$ complex show (Fig. 3c) clear and symmetrical diffraction spots, an observation which confirms the crystalline nature of the nanostructures. Although SEM and TEM can provide details of the morphology of $\boldsymbol{\alpha} \bullet \mathbf{B r}$, more detailed atomic-level structural information is required in order to understand the non-covalent bonding forces driving this highly selective molecular selfassembly process.

Co-crystallisation by slow vapour diffusion of ${ }^{i} \mathrm{PrOH}$ into a dilute aqueous solution of $\mathrm{KAuBr}_{4}$ and $\alpha$-CD afforded single crystals of $\alpha \bullet B \mathbf{B}$, which were suitable for X-ray crystallography. In the single-crystal superstructure (Fig. $4 \mathrm{a}-\mathrm{c}$ ) of $\boldsymbol{\alpha} \bullet \mathbf{B r}$, two $\alpha$-CD tori are observed to be held together by means of intermolecular hydrogen bonding between the secondary $\left(2^{\circ}\right)$ hydroxyl faces of adjacent $\alpha$-CD tori, which adopt a head-to-head packing arrangement, forming a supramolecular dimer. The dimer also serves the role of a second-sphere coordination cavitand occupied by the hexaaqua $\mathrm{K}^{+}$ion, $\left(\left[\mathrm{K}_{(}\left(\mathrm{OH}_{2}\right)_{6}\right]^{+}\right)$which adopts an equatorially distorted octahedral geometry with very short $\mathrm{K}-\mathrm{O}$ distances $^{38,39}$ ranging from 2.37(1) to 2.44(1) $\AA$ (average 2.39 $\AA$ ). We surmise that this superstructure forms in order for the

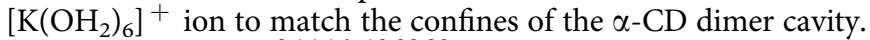
It has been shown $8,14,16-18,38,39$ previously that a few metal complexes, such as [12]crown- $4 \bullet \mathrm{KCl}$ (ref. 39) and metallocenium salts ${ }^{16-18}$, can form second-sphere coordination adducts ${ }^{25-27}$ with CDs. Although, generally speaking, naked $\mathrm{K}^{+}$ions are incorporated interstitially between CD columns and are directly first-sphere coordinated with the hydroxyl groups of the

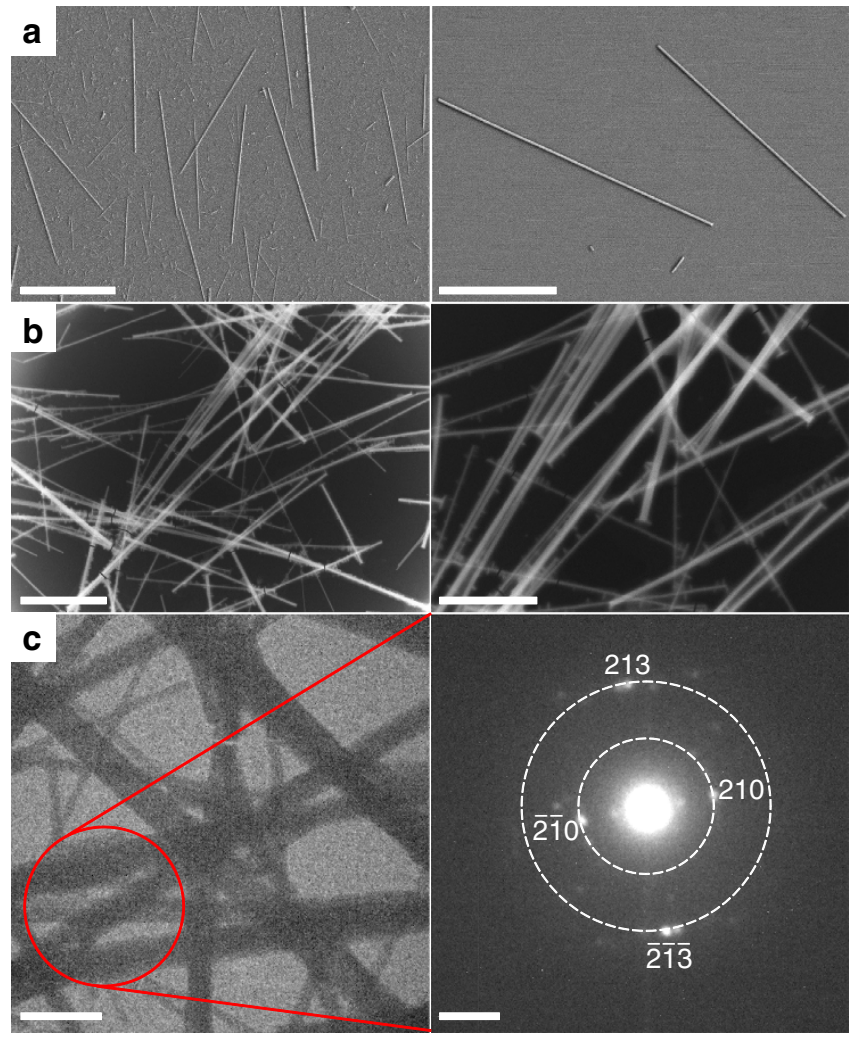

Figure 3 | Morphology of the nanostructures of $\alpha \cdot \mathbf{B r}$. (a) SEM images of a crystalline sample prepared by spin-coating an aqueous suspension of $\alpha \bullet \mathbf{B r}$ onto a silicon substrate, and then air-drying the suspension. (b) TEM images of $\boldsymbol{\alpha} \cdot \mathbf{B r}$ prepared by drop-casting an aqueous suspension of $\boldsymbol{\alpha} \cdot \mathbf{B r}$ onto a specimen grid covered with a thin carbon support film and air-dried. (c) Cryo-TEM image (left) and SAED pattern (right) of the nanostructures of $\boldsymbol{\alpha} \cdot \mathbf{B r}$. As the selected area includes several crystals with different orientations and the crystals are so small that the diffraction intensities are relatively weak, we can assign the diffraction rings composed of diffraction dots but not the specific angles between different diffraction dots from the same crystal. The scale bars in $\mathbf{a}$ and $\mathbf{b}$ are 25 (left),

5 (right), 10 (left), $5 \mu \mathrm{m}$ (right) and in $\mathbf{c}$ are $1 \mu \mathrm{m}$ (left) and $1 \mathrm{~nm}^{-1}$ (right), respectively.

$\mathrm{CDs}^{9,40-47}$, examples of hydrophilic fully hydrated $\mathrm{K}^{+}$ions encapsulated in the hydrophobic $\mathrm{CD}$ channels by means of second-sphere coordination are rare. The water molecules aligned

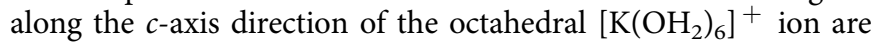
located statistically between the two symmetrical sites with 50:50 occupancies, which are related by an $\sim 7^{\circ}$ tilt about the $c$-axis. The square-planar $\left[\mathrm{AuBr}_{4}\right]^{-}$ions, centered between the primary $\left(1^{\circ}\right)$ hydroxyl faces of $\alpha$-CD (A) and the adjacent $\alpha$-CD (B), are disordered over two orientations with 50:50 occupancies and related by an $\sim 9^{\circ}$ rotation about the $c$-axis. Both $\alpha$-CD tori $A$ and $\mathbf{B}$ of the dimers in $\boldsymbol{\alpha} \bullet \mathbf{B r}$ are distorted elliptically and elongated along the $\left[\mathrm{AuBr}_{4}\right]^{-}$planes with reference to the glycosidic ring $\mathrm{O}$ atoms. Although it was not possible to locate the $\mathrm{H}$ atoms associated with the $\mathrm{H}_{2} \mathrm{O}$ molecules on the $\left[\mathrm{K}_{\left.\left(\mathrm{OH}_{2}\right)_{6}\right]^{+}}\right.$ ion, the distances between the $c$-axial $\mathrm{Br}$ and $\mathrm{O}$ atoms, which are 3.35(1) and 3.39(1) $\AA$, are comparable with the mean value of $3.339(7) \AA$ reported by Steiner ${ }^{48}$, an observation which suggests the presence of the significant $c$-axial $[\mathrm{O}-\mathrm{H} \cdots \mathrm{Br}-\mathrm{Au}]$ hydrogen bonding interactions (Supplementary Table S4). All four $\mathrm{Br}$ atoms are close to twelve $\mathrm{H} 5$ and $\mathrm{H} 6$ atoms on the primary $\left(1^{\circ}\right)$ faces of the glucopyranosyl rings (Fig. 1), with $[\mathrm{C}-\mathrm{H} \cdots \mathrm{Br}-\mathrm{Au}]$ contacts (Supplementary Table S3) of 
a
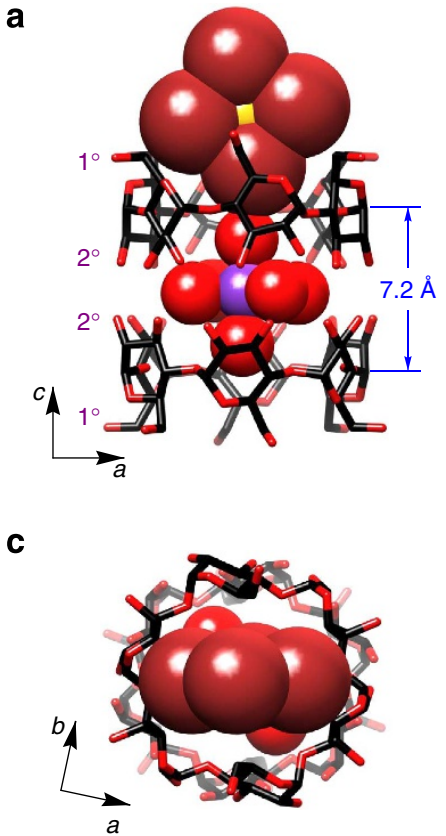

b

A

${ }^{B}{ }^{\prime}$

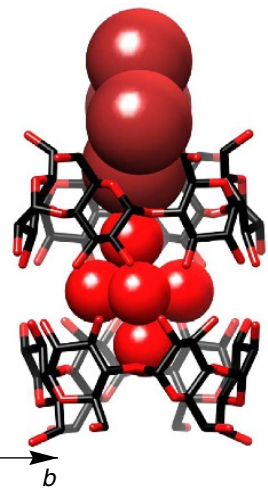

d
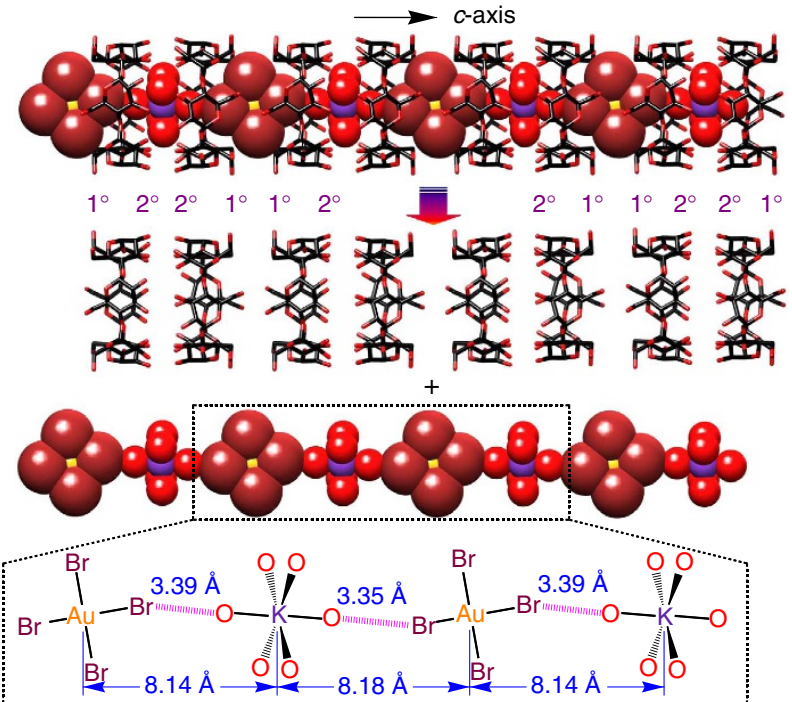

Figure 4 | Single-crystal $\mathbf{X}$-ray structure of $\alpha \cdot \mathbf{B r}$. The structure has the formula $\left\{\left[K\left(\mathrm{OH}_{2}\right)_{6}\right]\left[\mathrm{AuBr}_{4}\right] \subset(\alpha-\mathrm{CD})_{2}\right\}_{n}$. (a) Side-on view showing the orientation of the primary and secondary faces of the $\alpha-C D$ rings in the extended structure. (b) Side-on view illustrating the second-sphere

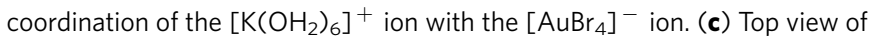
the arrangement of the $\left[\mathrm{AuBr}_{4}\right]^{-}$ion inside the cavity of $\alpha-C D$.

(d) Schematic illustration of the one-dimensional nanostructure extending along the $c$-axis in which the $\alpha$-CD tori form a continuous channel occupied by alternating $\left[\mathrm{K}\left(\mathrm{OH}_{2}\right)_{6}\right]^{+}$and $\left[\mathrm{AuBr}_{4}\right]^{-}$ions. Hydrogen atoms are omitted for clarity. C, black; O, red; $\mathrm{Br}$, brown; $\mathrm{Au}$, yellow; K, purple. Hydrogen bonds are depicted as purple dash lines.

$2.92-3.19 \AA$. The $[\mathrm{C}-\mathrm{H} \cdots \mathrm{Br}-\mathrm{Au}]$ hydrogen bonds ${ }^{13,49-51}$ favour an equal distribution of orientations of the $\left[\mathrm{AuBr}_{4}\right]^{-}$ anions around the $c$-axis. Accordingly, the dimers are stacked along the $c$-axis with $\left[\mathrm{AuBr}_{4}\right]^{-}$anions acting as linkers through multiple $[\mathrm{C}-\mathrm{H} \cdots \mathrm{Br}-\mathrm{Au}]$ hydrogen bonds with the $\alpha$-CDs in the $a-b$ plane and two $[\mathrm{O}-\mathrm{H} \cdots \mathrm{Br}-\mathrm{Au}]$ hydrogen bonds with the $\left[\mathrm{K}\left(\mathrm{OH}_{2}\right)_{6}\right]^{+}$ions oriented in the $c$-axial direction. These $\alpha$-CD dimers form parallel channels filled with $\left[\mathrm{K}\left(\mathrm{OH}_{2}\right)_{6}\right]^{+}$ cations and $\left[\mathrm{AuBr}_{4}\right]^{-}$anions, which line up in an alternating

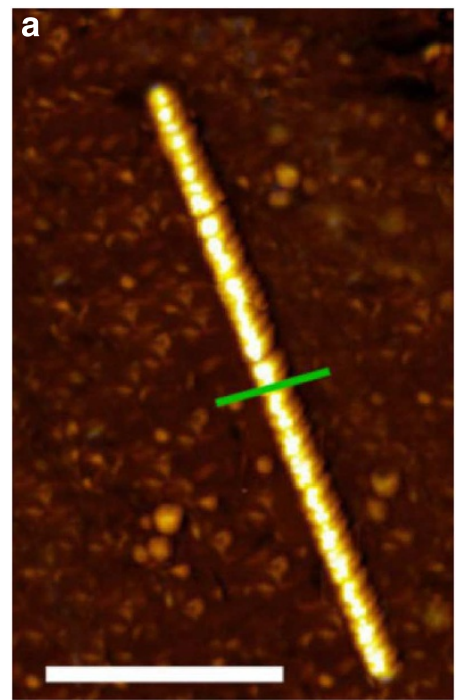

b

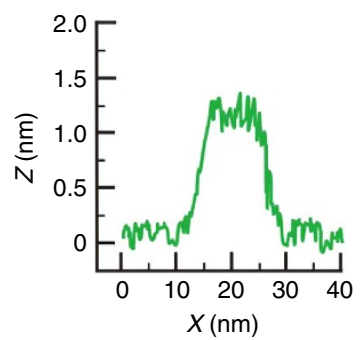

C

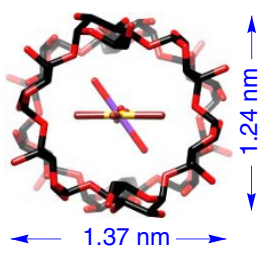

Figure 5 | AFM analysis of $\alpha \cdot B r$ on a mica surface. (a) AFM image of a spin-coated sample of $\boldsymbol{\alpha} \cdot \mathbf{B r}$ on a freshly cleaved mica surface. (b) The cross-sectional analysis of (a). (c) Dimensions of the cross-section of the one-dimensional $\alpha$-CD channel in $\boldsymbol{\alpha} \bullet \mathbf{B r}$. Scale bar, $100 \mathrm{~nm}$.

fashion to generate an infinite inorganic polyionic chain. This infinite cable-like supramolecular polymer can be dissected (Fig. 4d) structurally into head-to-head hydrogen-bonded $\alpha$-CD dimers oriented tail-to-tail with respect to each other, forming an outer sheath-like organic nanotube with a coaxial, inorganic polyionic, inner chain, core. Bundles of these nanostructures are then tightly packed through hydrogen bonding between columns to form a well-ordered array that constitutes the single crystal.

In order to confirm that the nanostructure of $\alpha \bullet \mathrm{Br}$, obtained as a co-precipitate by solution-phase synthesis, is in agreement with the superstructure present in the single crystal of $\alpha \cdot B r$, a centrifugally filtrated sample of the as-synthesized suspension of the supramolecular complex was analysed (Supplementary Fig. S9a) by powder XRD (PXRD). The experimental PXRD pattern matches very well with the simulated pattern based on the single-crystal X-ray data, suggesting that the superstructures present in the single crystal of $\boldsymbol{\alpha} \bullet \mathbf{B r}$ and the co-precipitated nanostructure are one and the same. In other words, the solution-phase synthesized one-dimensional nanostructures of $\alpha \bullet \mathbf{B r}$ are composed of single-crystalline bundles of one-dimensional molecular-level, cable-like, complexes (Fig. 4d) with high aspect ratios.

As solution-phase synthesis affords much smaller crystals, single-molecule imaging studies using AFM can provide dimensional information of the sample, such as its height, with subnanometre precision. In order to investigate the physical dimensions of the self-assembled nanostructure formed between $\mathrm{KAuBr}_{4}$ and $\alpha-\mathrm{CD}$ on surfaces, a sample for AFM measurement was grown directly on the substrate. A droplet of a very dilute aqueous solution of $\mathrm{KAuBr}_{4}(0.5 \mathrm{mM})$ and $\alpha-\mathrm{CD}(1 \mathrm{mM})$ was spin-coated on freshly cleaved mica and dried under ambient conditions. The AFM image reveals (Fig. 5a) that the individual nanoassemblies have lengths on the order of several hundred nanometres and an average height (Fig. 5b) of $1.3 \pm 0.2 \mathrm{~nm}$, which is consistent with the external diameter $(\sim 1.4 \mathrm{~nm})$ of $\alpha-C D$ (Fig. 5c). These experiments provide insight into the mechanism of the molecular self-assembly process whereby these singlemolecule-wide nanostructures are intermediates in the formation of the larger crystals observed by SEM and TEM. 
Front view
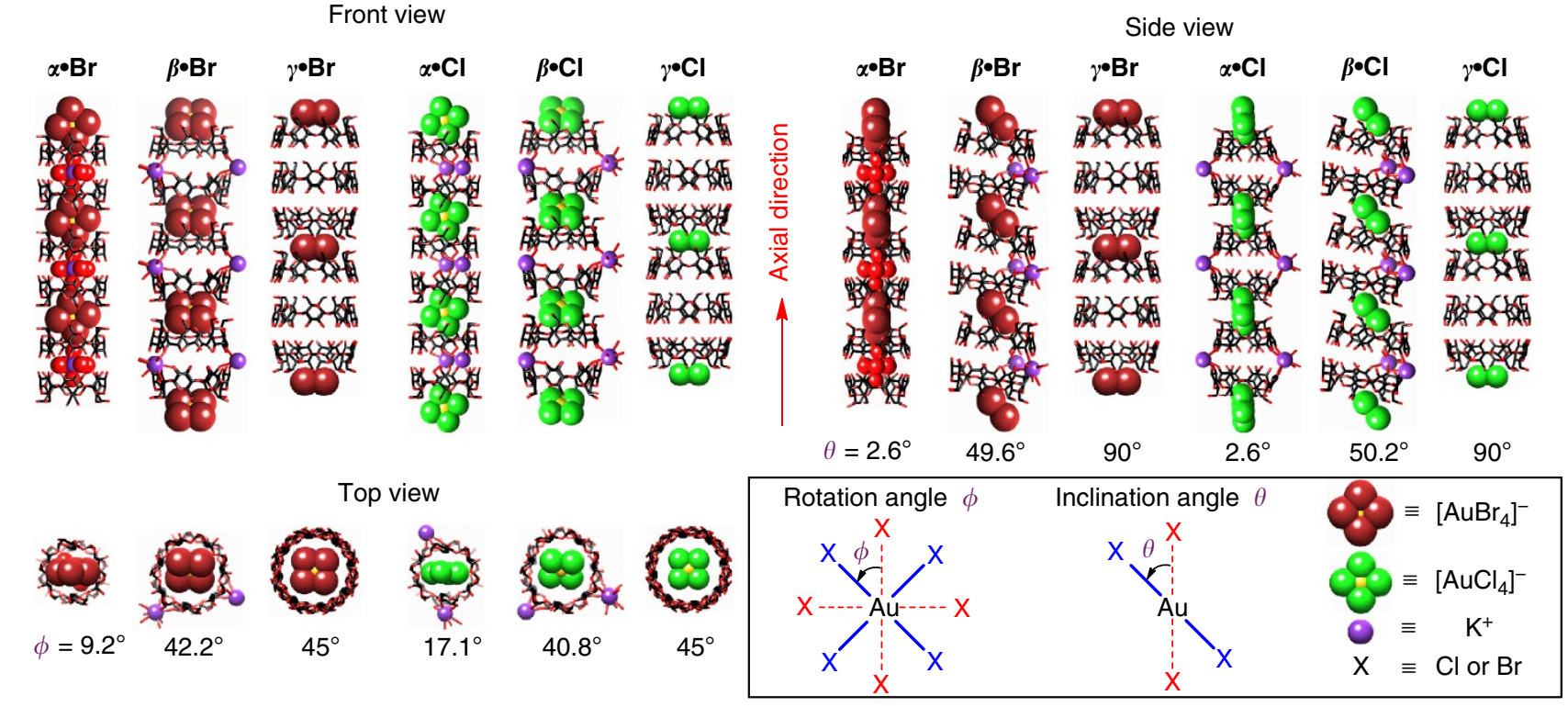

Side view

Figure 6 | Single-crystal superstructures of $\boldsymbol{\alpha} \bullet \mathbf{B r}, \boldsymbol{\alpha} \bullet \mathbf{C l}, \boldsymbol{\beta} \bullet \mathbf{B r}, \boldsymbol{\beta} \bullet \mathbf{C l}, \gamma \bullet \mathbf{B r}$ and $\gamma \bullet \mathbf{C l}$. The rotation angle of the $\left[\mathrm{AuX}_{4}\right]^{-}$anion viewed from the front is defined as $\phi$, and the inclination angle of the $\left[\mathrm{AuX}_{4}\right]^{-}$anion viewed from the side with respect to the central axis of the $C D$ tori is defined as $\boldsymbol{\theta}$. $\mathrm{C}$, black; $\mathrm{O}$, red; $\mathrm{Br}$, brown; $\mathrm{Cl}$, green; $\mathrm{Au}$, yellow; $\mathrm{K}$, purple.

Insight into the spontaneous co-precipitation of $\alpha \bullet B r$. It would appear that the spontaneous co-precipitation of the one-dimensional nanostructure of $\boldsymbol{\alpha \bullet B r}$ is highly selective as no similar phenomenon was observed from the other five combinations between $\mathrm{KAuX}_{4}$ salts $(\mathrm{X}=\mathrm{Cl}$ or $\mathrm{Br})$ with $\alpha$-, $\beta$ - and $\gamma$-CDs. In order to gain insight into the mechanism behind the formation of the nanostructure of $\boldsymbol{\alpha} \bullet \mathbf{B r}$ and the reason for its rapid coprecipitation, single crystals (Supplementary Table S1 and Supplementary Figs S2 - S7) of a series of inclusion complexes $\mathrm{KAuCl}_{4} \bullet(\boldsymbol{\alpha}-\mathrm{CD})_{2}(\boldsymbol{\alpha} \bullet \mathrm{Cl}), \mathrm{KAuBr}_{4} \bullet(\beta-\mathrm{CD})_{2} \quad(\boldsymbol{\beta} \bullet \mathbf{B r}), \mathrm{KAuCl}_{4} \bullet$ $(\beta-C D)_{2}(\boldsymbol{\beta} \bullet \mathrm{Cl}), \mathrm{KAuBr}_{4} \bullet(\gamma-\mathrm{CD})_{3}(\boldsymbol{\bullet} \bullet \mathbf{B r})$, and $\mathrm{KAuCl}_{4} \bullet(\gamma-\mathrm{CD})_{3}$ $(\gamma \bullet \mathrm{Cl})$ were grown employing similar slow vapour diffusion methods and subjected to single-crystal XRD analysis. In contrast to $\alpha \bullet \mathbf{B r}$, which adopts the orthorhombic space group $P 2_{1} 2_{1} 2$ (Supplementary Fig. S1), the crystal structure (Supplementary Fig. S2) of $\alpha \bullet \mathrm{Cl}$ is in the monoclinic $\left(\beta=90.041(4)^{\circ}\right)$ space group $P 2_{1}$. Both $\alpha$-CD tori of the dimers in $\alpha \bullet \mathbf{B r}$ and $\alpha \bullet \mathbf{C l}$ are elliptically distorted and elongated along the $\left[\mathrm{AuX}_{4}\right]^{-}$planes with respect to the glycosidic ring $\mathrm{O}$ atoms (Supplementary Fig. S3). A significant difference in the role exhibited by the $\mathrm{K}^{+}$ion was observed between $\boldsymbol{\alpha} \bullet \mathbf{B r}$ and $\boldsymbol{\alpha} \bullet \mathbf{C l}$. In $\boldsymbol{\alpha} \bullet \mathbf{C l}$, the $\mathrm{K}^{+}$ion is located outside the dimer cavity and enters into first-sphere coordination with seven primary hydroxyl groups belonging to two adjacent $\mathrm{CD}$ dimers. This observation suggests that the role of the $\mathrm{K}^{+}$ion is to act as a linker between adjacent CD dimers along the $b$-axis

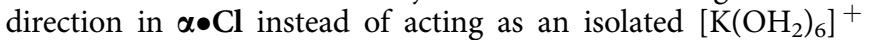
guest inside the CD dimer cavity in $\alpha \bullet B r$. The bridging of the $\mathrm{K}^{+}$ ions in $\alpha \bullet \mathbf{C l}$ along the $b$-axis results in the formation of onedimensional coordination polymer chains composed of alternating $\alpha$-CD dimers and $\mathrm{K}^{+}$ions, which then stack alternatively with $\left[\mathrm{AuCl}_{4}\right]^{-}$along the $a$-axis to constitute an extended twodimensional superstructure (Supplementary Fig. S8a). In order to compare the orientation of the square-planar anions $\left[\mathrm{AuBr}_{4}\right]^{-}$ and $\left[\mathrm{AuCl}_{4}\right]^{-}$in the $\mathrm{CD}$ channel, we define (i) the rotation angle of the $\left[\mathrm{AuX}_{4}\right]^{-}$anion viewed from the front (Fig. 6) as $\phi$, and (ii) the inclination angle of the $\left[\mathrm{AuX}_{4}\right]^{-}$anion viewed from the side with respect to the central axis of the $\mathrm{CD}$ tori (Fig. 6) as $\boldsymbol{\theta}$. The $\left[\mathrm{AuBr}_{4}\right]^{-}$anion in $\boldsymbol{\alpha} \bullet \mathbf{B r}$ has an orientation with $\boldsymbol{\phi}=9.2^{\circ}$ and $\boldsymbol{\theta}=2.6^{\circ}$, whereas the $\left[\mathrm{AuCl}_{4}\right]^{-}$anion in $\boldsymbol{\alpha} \bullet \mathbf{C l}$ has a more tilted orientation with $\phi=17.1^{\circ}$ and $\boldsymbol{\theta}=2.6^{\circ}$. All the differences in superstructure between $\boldsymbol{\alpha} \bullet \mathbf{B r}$ and $\boldsymbol{\alpha} \bullet \mathbf{C l}$, as well as the unique spontaneous co-precipitation of $\boldsymbol{\alpha} \bullet \mathbf{B r}$, can be ascribed to the subtle size differences between the $\left[\mathrm{AuBr}_{4}\right]^{-}$and $\left[\mathrm{AuCl}_{4}\right]^{-}$ anions. It is crucial to note that the average $\mathrm{Au}-\mathrm{Br}$ bond length of $2.42 \AA$ in $\boldsymbol{\alpha} \bullet \mathbf{B r}$ is only $0.15 \AA$ longer than the average $\mathrm{Au}-\mathrm{Cl}$ bond length of $2.27 \AA$ in $\boldsymbol{\alpha} \bullet \mathbf{C l}$ (Supplementary Table S2). This observation highlights the fact that the longer bond length in $\left[\mathrm{AuBr}_{4}\right]^{-}$facilitates the second-sphere coordination of $\alpha-\mathrm{CD}$ to

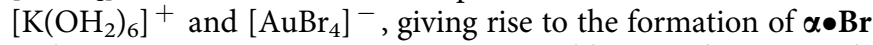
and its unique superstructure. In addition, this secondsphere coordination results in the encapsulation of $\left[\mathrm{K}_{(\mathrm{OH}} \mathrm{O}_{6}\right]^{+}$ cations inside the cavities of the $\alpha$-CD dimers, which we hypothesize restricts solvation of $\left.\left[\mathrm{K}_{(} \mathrm{OH}_{2}\right)_{6}\right]^{+}$cations by water molecules from the bulk-the reason for the observed rapid co-precipitation.

The $\beta$-CD complexes $\boldsymbol{\beta} \bullet \mathbf{B r}$ and $\boldsymbol{\beta} \bullet \mathbf{C l}$, as well as the $\gamma-\mathrm{CD}$ complexes $\gamma \bullet \mathbf{B r}$ and $\gamma \bullet \mathbf{C l}$, are all isomorphous, an observation which indicates that the subtle differences between $\left[\mathrm{AuBr}_{4}\right]^{-}$and $\left[\mathrm{AuCl}_{4}\right]^{-}$no longer result in significant changes in superstructure. The $\mathrm{K}^{+}$ions in $\boldsymbol{\beta} \bullet \mathbf{B r}$ and $\boldsymbol{\beta} \bullet \mathbf{C l}$ have similar bridging roles as they do in $\alpha \bullet \mathbf{C l}$, while the $\mathrm{K}^{+}$ions in $\gamma \bullet \mathbf{B r}$ and $\gamma \bullet \mathbf{C l}$ reside outside the $\mathrm{CD}$ channel and are disordered. The $\beta$-CD tori in $\boldsymbol{\beta} \bullet \mathbf{B r}$ and $\boldsymbol{\beta} \bullet \mathbf{C l}$ form head-to-head dimers similar to those in $\boldsymbol{\alpha} \bullet \mathbf{C l}$, whereas the $\gamma$-CDs in $\gamma \bullet \mathbf{B r}$ and $\gamma \bullet \mathbf{C l}$ form head-to-tail/ head-to-head trimeric repeating units. Moreover, $\beta$-CD dimers in $\boldsymbol{\beta} \bullet \mathbf{B r}$ and $\boldsymbol{\beta} \bullet \mathbf{C l}$ form zig-zag two-dimensional layered superstructures (Supplementary Fig. S8b and c). One common feature which describes all six complexes are that the $\mathrm{CD}$ rings stack along the longitudinal axes with $\left[\mathrm{AuX}_{4}\right]^{-}$anions acting as bridges, which are located inside the $\mathrm{CD}$ channels and are supported between the primary faces of the adjacent $\mathrm{CD}$ rings by $[\mathrm{C}-\mathrm{H} \cdots \mathrm{X}-\mathrm{Au}]$ hydrogen bonds, forming one-dimensional superstructures. With the expansion in size ongoing from $\alpha$ - to $\gamma$-CD tori, the angle $\phi$ increases from 9.2 to $45^{\circ}$ for $\left[\mathrm{AuBr}_{4}\right]^{-}$ and from 17.1 to $45^{\circ}$ for $\left[\mathrm{AuCl}_{4}\right]^{-}$, while the angle $\boldsymbol{\theta}$ increases from 2.6 to $90^{\circ}$ for $\left[\mathrm{AuBr}_{4}\right]^{-}$and $\left[\mathrm{AuCl}_{4}\right]^{-}$(Fig. 6), respectively. We hypothesize that this trend of $\left[\mathrm{AuX}_{4}\right]^{-}$to lie flatter is to shorten the length of the $[\mathrm{C}-\mathrm{H} \cdots \mathrm{X}-\mathrm{Au}]$ hydrogen bonds as 
much as possible and so facilitates the formation of the most stable host-guest superstructures. Except for $\boldsymbol{\alpha} \bullet \mathbf{B r}$ in which the $\mathrm{CD}$ channels are filled up by $\left.\left[\mathrm{K}_{(\mathrm{OH}}\right)_{6}\right]^{+}$and $\left[\mathrm{AuBr}_{4}\right]^{-}$, the other five complexes demonstrate (Fig. 6) 'bamboo'-like superstructures with isolated empty capsules formed by CD channels segmented by $\left[\mathrm{AuX}_{4}\right]^{-}$, and the $\mathrm{K}^{+}$cations are not encapsulated by the CD cavities. We suspect that the superstructures for these fives complexes result in the exposure of the $\mathrm{K}^{+}$cations to water molecules from the bulk, keeping these complexes solvated, and hence restricting precipitation.

Stability and porosity of all complexes. In order to assess the stability of all six complexes after activation using supercritical $\mathrm{CO}_{2}$ (refs 52,53) (see Methods), we first of all examined their thermal stabilities using thermogravimetric analysis (TGA). TGA traces (Supplementary Fig. S10) for all complexes start to show significant weight loss at $150^{\circ} \mathrm{C}$, suggesting that the samples are fully evacuated, while thermal decomposition occurs at temperatures over $150^{\circ} \mathrm{C}$.

In order to examine sample structural stability upon activation, PXRD analyses (Supplementary Fig. S9) were carried out on assynthesized and activated samples. The well-matched PXRD patterns of as-synthesized and activated samples of $\boldsymbol{\alpha} \bullet \mathbf{B r}$ confirm that its superstructure remains intact upon activation despite the lack of first-sphere coordination of $\mathrm{K}^{+}$ions between $\mathrm{CD}$ dimers. Comparison of the PXRD patterns of as-synthesized and activated samples of $\boldsymbol{\alpha} \bullet \mathbf{C l}, \boldsymbol{\beta} \bullet \mathbf{B r}$ and $\boldsymbol{\beta} \bullet \mathbf{C l}$ confirms the stability and crystallinity of their superstructures, which are formed by hydrogen bonding and $\mathrm{K}^{+}$ion coordination, upon activation. In contrast to these three samples, the activated samples of $\gamma \bullet \mathbf{B r}$ and $\gamma \bullet \mathbf{C l}$ were found to be amorphous by PXRD, an observation which indicates that the fully hydrogen-bonded structures of $\gamma \bullet \mathbf{B r}$ and $\gamma \bullet \mathbf{C l}$ are unstable and collapse after activation in the absence of $\mathrm{K}^{+}$ion coordination.

The surface areas and porosities of all complexes were examined by $\mathrm{CO}_{2}$ adsorption at $273 \mathrm{~K}$ (Supplementary Figs S11 and $\mathrm{S} 12)$. The isotherm of $\boldsymbol{\alpha} \bullet \mathbf{B r}$ reveals a poor uptake and a capacity of only $3.5 \mathrm{~cm}^{3} \mathrm{~g}^{-1}$ at 1 bar, corresponding to a BruhauerEmmett-Teller (BET) surface area of $35 \mathrm{~m}^{2} \mathrm{~g}^{-1}$. This observation stands in sharp contrast to $\boldsymbol{\alpha} \bullet \mathbf{C l}$, which shows a modest uptake ability of $23 \mathrm{~cm}^{3} \mathrm{~g}^{-1}$ at 1 bar with a BET surface area of $210 \mathrm{~m}^{2} \mathrm{~g}^{-1}$. This not insignificant difference can be attributed to their structural dissimilarities, in that the isolated capsules formed by segmentation of $\alpha$-CD channels with $\left[\mathrm{AuX}_{4}\right]^{-}$are empty in

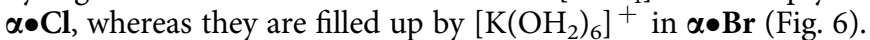
$\boldsymbol{\beta} \bullet \mathbf{B r}$ and $\boldsymbol{\beta} \bullet \mathbf{C l}$ have empty capsules, similar to those in $\boldsymbol{\alpha \bullet C l}$, and so also show modest uptakes and comparable BET surface areas $\left(224 \mathrm{~m}^{2} \mathrm{~g}^{-1}\right.$ for $\boldsymbol{\beta} \bullet \mathbf{B r}$ and $138 \mathrm{~m}^{2} \mathrm{~g}^{-1}$ for $\left.\boldsymbol{\beta} \bullet \mathbf{C l}\right)$. Both $\gamma \bullet \mathbf{B r}$ and $\gamma \bullet \mathrm{Cl}$ exhibit very low uptakes and BET surface areas, as the activation turned them into amorphous powders ${ }^{54}$, as indicated by PXRD (Supplementary Fig. S9). These results are consistent with our hypothesis that co-precipitation of $\alpha \bullet \mathbf{B r}$ is a result of the $\alpha$-CD dimer cavities being filled-that is, the $\left.\left[\mathrm{K}_{(\mathrm{OH}}\right)_{6}\right]^{+}$cations are encapsulated and restricted from solvation.

Selective isolation of gold from gold-bearing raw materials. The selective co-precipitation of $\boldsymbol{\alpha} \bullet \mathbf{B r}$ between $\alpha-C D$ and $\mathrm{KAuBr}_{4}$ has prompted us to investigate if the high selectivity of $\alpha-\mathrm{CD}$ rings towards trapping $\left[\mathrm{AuBr}_{4}\right]^{-}$anions is also effective in the presence of other square-planar noble metal complexes, for example, $\left[\mathrm{PtX}_{4}\right]^{2-}$ and $\left[\mathrm{PdX}_{4}\right]^{2-}(\mathrm{X}=\mathrm{Cl}, \mathrm{Br})$. In an attempt to obtain an estimate of the separation efficiency, $\alpha-C D$ $(0.2 \mathrm{mmol} \times 2)$ was added separately to (i) a solution $(3 \mathrm{ml})$ containing $\mathrm{KAuBr}_{4}(33 \mathrm{mM}), \mathrm{K}_{2} \mathrm{PtBr}_{4}(26 \mathrm{mM}$, saturated) and $\mathrm{K}_{2} \mathrm{PdBr}_{4}(33 \mathrm{mM})$ (Mixture 1), and also to (ii) another solution

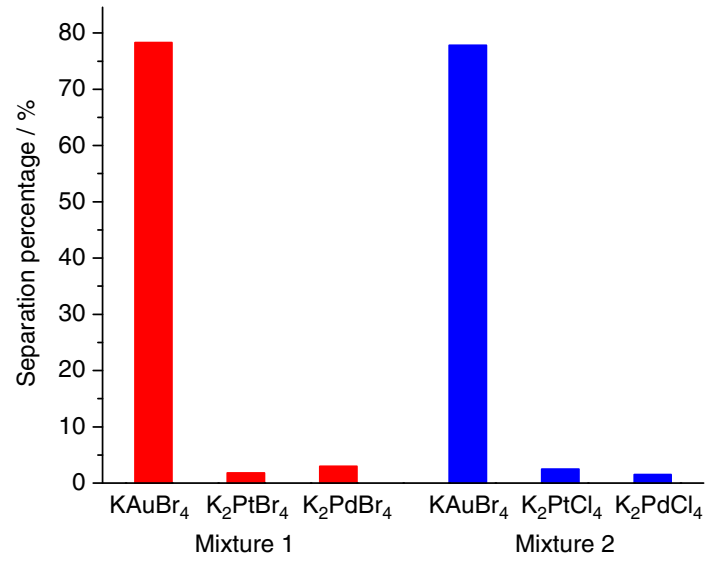

Figure 7 | Selective precipitation and separation of gold. The separation percentage, from mixtures 1 (red) and 2 (blue), is defined as $\left(C_{b}-C_{a}\right) / C_{b}$, where $C_{b}$ and $C_{a}$ are the concentrations of each metal before and after addition of $\alpha-C D$, respectively.

(3 ml) of $\mathrm{KAuBr}_{4}(33 \mathrm{mM}), \mathrm{K}_{2} \mathrm{PtCl}_{4}(24 \mathrm{mM}$, saturated) and $\mathrm{K}_{2} \mathrm{PdCl}_{4}(33 \mathrm{mM})$ (Mixture 2), respectively. Pale brown precipitates formed in both solutions immediately after the addition. Both precipitates were filtered, and the filtrates were diluted and subjected to inductively coupled plasma optical emission spectroscopy (ICP-OES) elemental analysis to determine the residual amounts of $\mathrm{Au}, \mathrm{Pt}$ and $\mathrm{Pd}$ remaining in the mother liquor. The separation percentages for $\mathrm{Au}, \mathrm{Pt}$ and $\mathrm{Pd}$ in both mixtures are defined by comparing contents of $\mathrm{Au}, \mathrm{Pt}$ and $\mathrm{Pd}$ in the two mixtures before and after addition of $\alpha$-CD. The ICP-OES analysis results show (Fig. 7) that $78.3 \%$ of $\mathrm{Au}$ in Mixture 1 and $77.8 \%$ of $\mathrm{Au}$ in Mixture 2 were separated out of solution, whereas $<3 \%$ of $\mathrm{Pt}$ and $\mathrm{Pd}$ was removed from both mixtures, values which are within the error limit of the experiment. These results reveal that the capture of $\left[\mathrm{AuBr}_{4}\right]^{-}$ions by $\alpha-\mathrm{CD}$ to form $\boldsymbol{\alpha} \bullet \mathbf{B r}$ in Mixture 1 and Mixture 2 is a highly selective process even in the presence of other noble metals and augurs well for developing a low cost and environmentally benign procedure for the separation of gold from complex mixtures of similar metal salts.

In order to explore the practical potential of the selective coprecipitation of $\boldsymbol{\alpha} \bullet \mathbf{B r}$ for gold recovery, we have employed goldbearing scrap as the raw material to develop a laboratory scale gold recovery process. Taking into account that the $\mathrm{pH}$ of the $\left[\mathrm{AuBr}_{4}\right]^{-}$-bearing solution may vary in practice, we first of all studied the effect of $\mathrm{pH}$ on the co-precipitation of $\alpha$-CD with $\left[\mathrm{AuBr}_{4}\right]^{-}$. Co-precipitation experiments conducted by adding $\alpha$-CD into $\left[\mathrm{AuBr}_{4}\right]^{-}$solutions $(50 \mathrm{mM})$ of various $\mathrm{pH}(1.4-5.9)$ indicate (see Methods and Supplementary Fig. S13) a trend in the residual concentration of $\left[\mathrm{AuBr}_{4}\right]^{-}$in the filtrate after filtration to remove the co-precipitates. When the $\mathrm{pH}$ is increased from 1.4 to 2.5 , the residual concentration of $\left[\mathrm{AuBr}_{4}\right]^{-}$decreases to $\sim 6.8 \mathrm{mM}$-which is consistent with the bulk solubility of $\boldsymbol{\alpha \bullet B r}$ in water-and remains constant at this value until $\mathrm{pH} 5.9$ is attained. This result reveals that the co-precipitation of $\alpha$-CD with $\left[\mathrm{AuBr}_{4}\right]^{-}$is dependent on $\mathrm{pH}$, and that the $\mathrm{pH}$ range 2.5-5.9 is the suitable one to initiate this co-precipitation process. We have managed (see Fig. 8 and Methods) to convert two scrap gold-bearing alloys containing $58 \%$ wt of $\mathrm{Au}$ and $42 \%$ wt of other metals ( $\mathrm{Zn}, \mathrm{Cu}$ and $\mathrm{Ag}$ ) into $\mathrm{HAuBr}_{4}$ by dissolving them with a mixture of concentrated $\mathrm{HBr}$ and $\mathrm{HNO}_{3}$ as the etchant solution. On the basis of this $\mathrm{pH}$ experiment, $\mathrm{KOH}$ was used to neutralize both dissolved gold solutions to $\mathrm{pH} 4-6$, and consequently convert $\mathrm{HAuBr}_{4}$ to $\mathrm{KAuBr}_{4}$. When $\alpha$-CD was added to both solutions, the co-precipitation of $\boldsymbol{\alpha} \bullet \mathbf{B r}$ occurred immediately, 


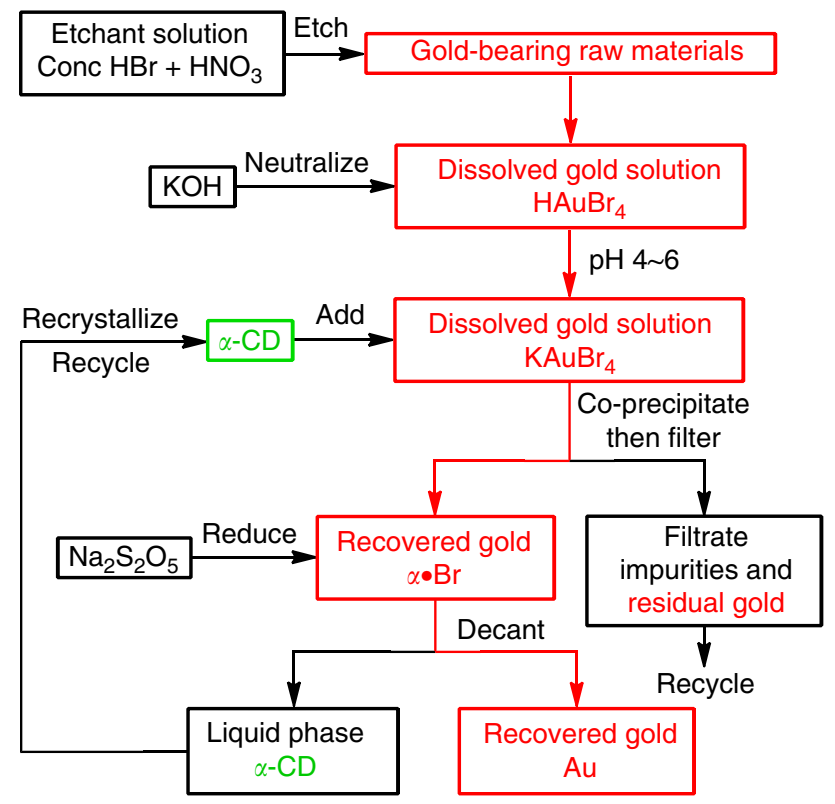

Figure 8 | Gold recovery process flow diagram. Red arrows indicate the flow direction of the gold recovery. $\mathrm{Na}_{2} \mathrm{~S}_{2} \mathrm{O}_{5}$ : Sodium metabisulfite.

even in the presence of the significant amounts of $\mathrm{Zn}$ and $\mathrm{Cu}$ salts. The co-precipitated $\alpha \cdot \mathbf{B r}$ complex-namely, recovered gold-was separated from impurities by filtration and then reduced with a reductant, such as $\mathrm{Na}_{2} \mathrm{~S}_{2} \mathrm{O}_{5}$, to afford the recovered gold metal. The residual gold in the filtrate can be recycled while $\alpha-C D$ can be reused by recrystallisation from the filtrate. This laboratory scale process is highly selective for gold, as well as being economic, fast and feasible. As it doesn't involve the use of toxic inorganic cyanides, this process is much more environmentally benign in comparison with the universally accepted cyanidation process ${ }^{2}$. Further optimization of process conditions and parameters is ongoing in our laboratories.

\section{Discussion}

The rapid solution-phase self-assembly of $\mathrm{KAuBr}_{4}$ and $\alpha-\mathrm{CD}$ leads to the formation of a host-guest complex $(\boldsymbol{\alpha} \bullet \mathrm{Br})$, which coprecipitates as needle-like crystals with a superstructure wherein $\alpha$-CD nanochannels are filled up by $\left[\mathrm{K}\left(\mathrm{OH}_{2}\right)_{6}\right]^{+}$and $\left[\mathrm{AuBr}_{4}\right]^{-}$ ion pairs in an alternating fashion through multiple preorganized, hydrogen bonding interactions. The unique formation and coprecipitation of $\boldsymbol{\alpha} \cdot \mathbf{B r}$ suggest that this self-assembly process arises as a consequence of the perfect structural correspondence between the stereoelectronics associated with $\left.\left[\mathrm{K}_{(\mathrm{OH}}\right)_{6}\right]^{+}$, $\left[\mathrm{AuBr}_{4}\right]^{-}$and $\alpha-\mathrm{CD}$. The axial $[\mathrm{O}-\mathrm{H} \cdots \mathrm{Br}-\mathrm{Au}]$ and the equatorial $[\mathrm{C}-\mathrm{H} \cdots \mathrm{Br}-\mathrm{Au}]$ hydrogen bonding-triggered second-sphere coordination has an indispensible role in governing the formation of $\alpha \cdot \mathbf{B r}$ and its rapid co-precipitation. A fundamental understanding of these multiple non-covalent bonding phenomena provides insight into the nature of the molecular self-assembly processes, wherein extremely subtle changes in substrates lead to different superstructures and properties. This specific co-precipitation procedure establishes a motif for the selective capture of gold in the form of $\mathrm{KAuBr}_{4}$, starting from gold-bearing raw materials and mixtures of six square-planar anions $\left(\left[\mathrm{AuX}_{4}\right]^{-},\left[\mathrm{PtX}_{4}\right]^{2-}\right.$ and $\left[\mathrm{PdX}_{4}\right]^{2-}$, $\mathrm{X}=\mathrm{Cl}, \mathrm{Br}$ ). The research highlights the potential application of a green technology for an economic recovery process of gold by using the inexpensive and environmentally benign $\alpha-C D$.

\section{Methods}

Materials. Chemicals were purchased as reagent grade from Aldrich and used without further purification. High purity water was generated by a Milli-Q apparatus (Millipore).

Formation and characterization of $\alpha \bullet \mathrm{Br}$. An aqueous solution of $\mathrm{KAuBr}_{4}$ $(25 \mathrm{mM}, 1 \mathrm{ml})$ was added to an aqueous solution of $\alpha$-CD $(50 \mathrm{mM}, 1 \mathrm{ml})$ at room temperature. A glossy pale brown suspension formed within a few minutes of shaking. Centrifugal filtration and drying under vacuum of the suspension allows isolation of the $\boldsymbol{\alpha} \cdot \mathbf{B r}$ complex as a pale brown powder in $\sim 70 \%$ yield. The phase purity of this complex was confirmed (Supplementary Fig. S9a) by PXRD. The as-synthesized suspension was spin-coated on a silicon wafer and dried under air. SEM images were obtained using a Hitachi S-4800 FS-SEM. TEM images were obtained on a Hitachi H-2300 TEM operating at $80 \mathrm{kV}$. SAED patterns were taken with a Hitachi H-8100 instrument at a temperature of $113 \mathrm{~K}$. Powder XRD data were collected on a Rigaku ATXG X-ray diffractometer using $\mathrm{Cu}-\mathrm{K}_{\alpha}$ radiation $(\lambda=1.54178 \AA, 50 \mathrm{kV}, 240 \mathrm{~mA})$ at room temperature. The observed intensities are in very good agreement with the calculated diffraction pattern based on the single-crystal data (Supplementary Fig. S9a).

Crystallisations and $\mathrm{X}$-ray analyses for all complexes. For $\alpha \bullet \mathrm{Br}$ : Aqueous solutions of $\mathrm{KAuBr}_{4}(3.33 \mathrm{mM}, 1 \mathrm{ml})$ and $\alpha$-CD $(6.67 \mathrm{mM}, 1 \mathrm{ml})$ were mixed together. For $\boldsymbol{\alpha} \bullet \mathrm{Cl}, \boldsymbol{\beta} \bullet \mathrm{Br}, \boldsymbol{\beta} \bullet \mathrm{Cl}, \boldsymbol{\gamma} \bullet \mathrm{Br}$, and $\gamma \bullet \mathrm{Cl}$ : Aqueous solutions of $\mathrm{KAuX}_{4}$ $(20 \mathrm{mM}, 1 \mathrm{ml})$ and CDs $(26.7 \mathrm{mM}, 1.5 \mathrm{ml})$ were mixed together and passed through a Pall syringe filter (pore size $0.45 \mu \mathrm{m})$ into culture tubes $(6 \times 50 \mathrm{~mm})$. The tubes were allowed to stand at room temperature in a closed $20 \mathrm{ml}$ scintillation vial containing $\mathrm{EtOH}$ or $\mathrm{MeOH}(5 \mathrm{ml})$. After about 1 week, the crystals, which appeared in the tubes, were selected and mounted using oil (Infineum V8512) on a glass fibre and transferred to the cold gas stream cooled by liquid $\mathrm{N}_{2}$ on Bruker APEX-II CCDs (charge-coupled devices) with graphite monochromated $\mathrm{Mo}-\mathrm{K}_{\alpha}$ or $\mathrm{Cu}-\mathrm{K}_{\alpha}$ radiation. The structures were solved by direct methods and refined subsequently using OLEX2 software. CCDC 918412 - 918417 contain the supplementary crystallographic data for this article. These data can be obtained free of charge from the Cambridge Crystallographic Data Centre via www.ccdc.cam.ac.uk/ data_request/cif.

AFM Measurements. Tapping mode AFM measurements were performed using a multimode scanning probe microscope with a Nanoscope $3 \mathrm{~A}$ controller (Digital Instruments, Veeco Probes), operating at room temperature in air. AFM images were recorded on freshly cleaved mica surfaces (Ruby Muscovite mica, SJ Mica \& Trading), prepared by spin-coating a droplet of a very dilute aqueous solution of $\mathrm{KAuBr}_{4}(0.5 \mathrm{mM})$ and $\alpha$-CD $(1 \mathrm{mM})$ and dried in a chemical hood at room temperature. AFM studies were executed with a microfabricated ultrasharp silicon cantilever (model NSG-01, NT-MDT Co.) using the tapping mode at their resonant frequency $(149 \mathrm{kHz})$, having a spring constant of $5 \mathrm{~N} \mathrm{~m}^{-1}$ and a normal tip radius of $\sim 10 \mathrm{~nm}$. AFM images were recorded at scan frequencies of $1-2 \mathrm{~Hz}$ with minimal loading forces applied and optimized feedback parameters. Several images were obtained at separate locations across the mica surfaces to ensure a high degree of reproducibility of the recorded molecular nanostructures. All the images consist of $512 \times 512$ pixels and were analysed by means of Nanoscope $5.12 \mathrm{r} 5$ software. The width of the nanostructure of $\boldsymbol{\alpha} \mathbf{B} \mathbf{B r}$ was corrected owing to the tip convolution by taking into account a tip radius of $10 \mathrm{~nm}$ and the height of the nanostructure of $1.3 \pm 0.2 \mathrm{~nm}$, determined from the topographical profile, we estimate a corrected width of $\sim 1.4 \mathrm{~nm}$.

TGA Measurements. TGA experiments were performed on a Mettler Toledo TGA/DSC 1 Star ${ }^{\mathrm{e}}$ System (Schwerzenbach, Switzerland) interfaced with a PC using Star ${ }^{\mathrm{e}}$ software (version 9.10). Samples were placed in alumina pans and heated at a rate of $10^{\circ} \mathrm{C} \mathrm{min}^{-1}$ from 25 to $800^{\circ} \mathrm{C}$ under a nitrogen atmosphere.

Gas adsorption experiments. Supercritical $\mathrm{CO}_{2}$ drying was performed using a Tousimis Samdri PVT-30 critical point dryer (Tousimis, Rockville, MD, USA). $\mathrm{CO}_{2}$ isotherm measurements were carried out on an Autosorb-1MP instrument (Quantachrome Instruments, Boynton Beach, FL). Measurements were performed at $273 \mathrm{~K}$ and were held constant using a Polyscience recirculating chiller (PolyScience, Niles, IL). After filtering the sample, it was transferred into a Tousimis Samdri-PVT-three-dimensional super-critical $\mathrm{CO}_{2}$ dryer. The temperature was lowered to $0{ }^{\circ} \mathrm{C}$, and the chamber was filled with liquid $\mathrm{CO}_{2}$ (ultrahigh grade $\mathrm{CO}_{2}$ with a siphon from Air-Gas Inc., was used). The sample was soaked for $8 \mathrm{~h}$ in total, venting for $5 \mathrm{~min}$ every $2 \mathrm{~h}$. The chamber was then heated to $40^{\circ} \mathrm{C}$, and the supercritical $\mathrm{CO}_{2}$ was bled off at a rate of $1 \mathrm{ml} \mathrm{min}^{-1}$ until the chamber reached ambient pressure $(\sim 12 \mathrm{~h})$. The chamber was opened and the sample was quickly sealed and taken into an argon atmosphere glove box for further manipulations. The dried sample was transferred into a preweighed glass sample tube which was sealed and quickly transferred to a system providing $10^{-4}$ torr dynamic vacuum. The sample was kept under vacuum at room temperature for $18 \mathrm{~h}$ and was then used for $\mathrm{CO}_{2}$ adsorption measurements. After measurement, the sample was returned to the argon atmosphere glove box and a final mass was calculated. 
ICP-OES analyses. ICP-OES was carried out on a Varian ICP-OES spectrometer (Varian, Walnut Creek, CA) equipped with a CCD detector and argon plasma that cover the spectral range from 175 to $785 \mathrm{~nm}$. The samples, filtered through a $0.45-\mu \mathrm{m}$ Acrodisc, were diluted with ultrapure $\mathrm{H}_{2} \mathrm{O}$ and analysed for contents of $\mathrm{Au}, \mathrm{Pt}$ and $\mathrm{Pd}$ as compared with standard solutions.

pH experiments. Seven $\left[\mathrm{AuBr}_{4}\right]^{-}$solutions $(50 \mathrm{mM}, 2 \mathrm{ml})$ with $\mathrm{pH}$ values of 1.4 $1.7,1.8,1.9,2.5,4.8$ and 5.9 were prepared by neutralizing identical amounts of $\mathrm{HAuBr}_{4}$ with different amounts of $\mathrm{KOH}$ in water. The $\mathrm{pHs}$ of these solutions were measured with a Hanna Checker $\mathrm{pH}$ metre. When $\alpha$-CD $(0.2 \mathrm{mmol} \times 7)$ was added to the above seven solutions, the co-precipitation occurred immediately. The co-precipitates were removed by filtration, and the filtrates were then diluted and analysed for their residual concentrations of $\left[\mathrm{AuBr}_{4}\right]^{-}$by ICP-OES

Process for gold recovery from gold-bearing materials. A red gold alloy scrap (58\% wt $\mathrm{Au}$ and $42 \%$ wt $\mathrm{Cu}$ and $\mathrm{Ag}$, \% wt $\mathrm{Cu}>\mathrm{Ag}$ ) and a yellow gold alloy scrap (58\% wt $\mathrm{Au}$ and $42 \%$ wt $\mathrm{Cu}, \mathrm{Zn}$ and $\mathrm{Ag}$, \% wt $\mathrm{Ag}>\mathrm{Cu}>\mathrm{Zn}$ ) were employed as gold-bearing raw materials to explore a laboratory scale gold recovery process. General procedure (Fig. 8): the gold-bearing raw material $(250 \mathrm{mg})$ was dissolved in a mixture $(4 \mathrm{ml})$ of concentrated $\mathrm{HBr}$ and $\mathrm{HNO}_{3}(3 / 1, \mathrm{~V} / \mathrm{V})$. Then, the dissolved gold solution was neutralized to $\mathrm{pH} 4-6$ with $\mathrm{KOH}$ and filtered to remove insoluble silver bromide. When $\alpha$-CD $(1.48 \mathrm{mmol}, 1.44 \mathrm{~g})$ was added to the solution, the coprecipitation of $\boldsymbol{\alpha} \bullet \mathbf{B r}$ occurred immediately. Co-precipitated $\boldsymbol{\alpha} \bullet \mathbf{B r}-$ namely, recovered gold-was separated by filtration. The residual gold in the filtrate can be recycled with the next process. The solid-state $\boldsymbol{\alpha} \bullet \mathbf{B r}$ was dispersed into water, and then reduced with $\mathrm{Na}_{2} \mathrm{~S}_{2} \mathrm{O}_{5}(300 \mathrm{mg})$ to give the recovered gold metal as a precipitate. The recovered gold metal was collected by decanting off the aqueous, and the remaining $\alpha$-CD in the liquid phase recycled by recrystallisation. For the red gold alloy scrap sample, the recovered gold was obtained in $89 \%$ yield and $97 \%$ purity (ICP-OES). For the yellow gold alloy scrap sample, the recovered gold was obtained in $92 \%$ yield and $95 \%$ purity (ICP-OES).

\section{References}

1. Syed, S. Recovery of gold from secondary sources-A review. Hydrometallurgy 115-116, 30-51 (2012).

2. Rubo, A., Kellens, R., Reddy, J., Steier, N. \& Hasenpusch, W. Ullmann's Encyclopedia of Industrial Chemistry (Wiley-VCH Verlag $\mathrm{GmbH}, 2000$ )

3. Cram, D. J. \& Cram, J. M. Host-guest chemistry. Science 183, 803-809 (1974).

4. Nepogodiev, S. A. \& Stoddart, J. F. Cyclodextrin-based catenanes and rotaxanes. Chem. Rev. 98, 1959-1976 (1998).

5. Wenz, G., Han, B. -H. \& Müller, A. Cyclodextrin rotaxanes and polyrotaxanes. Chem. Rev. 106, 782-817 (2006).

6. Frampton, M. J. \& Anderson, H. L. Insulated molecular wires. Angew. Chem. Int. Ed. 46, 1028-1064 (2007).

7. Harada, A., Hashidzume, A., Yamaguchi, H. \& Takashima, Y. Polymeric rotaxanes. Chem. Rev. 109, 5974-6023 (2009).

8. Hapiot, F., Tilloy, S. \& Monflier, E. Cyclodextrins as supramolecular hosts for organometallic complexes. Chem. Rev. 106, 767-781 (2006).

9. Harata, K. Structural aspects of stereodifferentiation in the solid state. Chem Rev. 98, 1803-1828 (1998).

10. Li, G. \& McGown, L. B. Molecular nanotube aggregates of $\beta$ - and $\gamma$ cyclodextrins linked by diphenylhexatrienes. Science 264, 249-251 (1994).

11. Harada, A., Li, J. \& Kamachi, M. Double-stranded inclusion complexes of cyclodextrin threaded on poly(ethylene glycol). Nature 370, 126-128 (1994).

12. Harada, A., Li, J. \& Kamachi, M. The molecular necklace: a rotaxane containing many threaded $\alpha$-cyclodextrins. Nature 356, 325-327 (1992)

13. Alston, D. R., Slawin, A. M. Z., Stoddart, J. F., Williams, D. J. \& Zarzycki, R. Second sphere coordination adducts of phosphane-transition metal complexes with $\beta$-cyclodextrin and its methylated derivative. Angew. Chem. Int. Ed. Engl. 27, 1184-1185 (1988)

14. Alston, D. R., Slawin, A. M. Z., Stoddart, J. F. \& Williams, D. J. Cyclodextrins as second sphere ligands for transition metal complexes-The X-ray crystal structure of $\left[\mathrm{Rh}(\mathrm{cod})\left(\mathrm{NH}_{3}\right)_{2} \cdot \alpha\right.$-cyclodextrin $]\left[\mathrm{PF}_{6}\right] \cdot 6 \mathrm{H}_{2} \mathrm{O}$. Angew. Chem. Int. Ed. Engl. 24, 786-787 (1985).

15. Alston, D. R., Slawin, A. M. Z., Stoddart, J. F. \& Williams, D. J. The X-ray crystal structure of a 1:1 adduct between $\alpha$-cyclodextrin and cyclobutane-1, 1-dicarboxylatodiammineplatinum(II). J. Chem. Soc., Chem. Commun. 1602-1604 (1985)

16. Klingert, B. \& Rihs, G. Molecular encapsulation of transition-metal complexes in cyclodextrins. 1. Synthesis and X-ray crystal structure of $\left[\left(\eta^{5}-\mathrm{C}_{5} \mathrm{H}_{5}\right) \mathrm{Fe}\right.$ $\left.\left(\eta^{6}-\mathrm{C}_{6} \mathrm{H}_{6}\right)\right] \mathrm{PF}_{6} \cdot 2 \alpha-\mathrm{CD} \cdot 8 \mathrm{H}_{2} \mathrm{O}$. Organometallics 9, 1135-1141 (1990).

17. Klingert, B. \& Rihs, G. Molecular encapsulation of transition metal complexes in cyclodextrins. Part 2. Synthesis and crystal structures of 2:1 adducts between $\alpha$-cyclodextrin and metallocenium hexafluorophosphates $\left[\left(\eta^{5}-\mathrm{C}_{5} \mathrm{H}_{5}\right)_{2} \mathrm{M}\right] \mathrm{PF}_{6}$ $(\mathrm{M}=\mathrm{Fe}, \mathrm{Co}, \mathrm{Rh})$. J. Incl. Phenom. Macrocycl. Chem. 10, 255-265 (1991).

18. Klingert, B. \& Rihs, G. Molecular encapsulation of transition metal complexes in cyclodextrins. Part 3. Structural consequences of varying the guest geometry in channel-type inclusion compounds. J. Chem. Soc., Dalton Trans. 2749-2760 (1991).

19. Liu, Y., Zhao, Y. -L., Zhang, H. -Y. \& Song, H. -B. Polymeric rotaxane constructed from the inclusion complex of $\beta$-cyclodextrin and 4,4'-dipyridine by coordination with nickel(II) ions. Angew. Chem. Int. Ed. 42, 3260-3263 (2003).

20. Noltemeyer, M. \& Saenger, W. X-ray studies of linear polyiodide chains in $\alpha$-cyclodextrin channels and a model for the starch-iodine complex. Nature 259, 629-632 (1976)

21. Noltemeyer, M. \& Saenger, W. Topography of cyclodextrin inclusion complexes. 12. Structural chemistry of linear $\alpha$-cyclodextrin-polyiodide complexes. X-ray crystal structures of $(\alpha \text {-cyclodextrin })_{2} \cdot \mathrm{LiI}_{3} \cdot \mathrm{I}_{2} \cdot 8 \mathrm{H}_{2} \mathrm{O}$ and $(\alpha \text {-cyclodextrin })_{2} \cdot \mathrm{Cd}_{0.5} \cdot \mathrm{I}_{5} \cdot 27 \mathrm{H}_{2} \mathrm{O}$. Models for the blue amylose-iodine complex. J. Am. Chem. Soc. 102, 2710-2722 (1980).

22. Betzel, C. et al. ( $\beta$-Cyclodextrin $)_{2} \cdot \mathrm{KI}_{7} \cdot 9 \mathrm{H}_{2} \mathrm{O}$. Spatial fitting of a polyiodide chain to a given matrix. J. Incl. Phenom. Macrocycl. Chem. 1, 181-191 (1983).

23. Cacialli, F. et al. Cyclodextrin-threaded conjugated polyrotaxanes as insulated molecular wires with reduced interstrand interactions. Nat. Mater. 1, 160-164 (2002).

24. Wenz, G. Cyclodextrins as building blocks for supramolecular structures and functional units. Angew. Chem. Int. Ed. Engl. 33, 803-822 (1994).

25. Colquhoun, H. M., Stoddart, J. F. \& Williams, D. J. Second-sphere coordination-a novel rǒle for molecular receptors. Angew. Chem. Int. Ed. Engl 25, 487-507 (1986).

26. Harada, A. \& Takahashi, S. Preparation and properties of cyclodextrinferrocene inclusion complexes. J. Chem. Soc., Chem. Commun. 645-646 (1984)

27. Harada, A., Yamamoto, S. \& Takahashi, S. Preparation and properties of inclusion compounds of transition-metal complexes of cycloocta-1,5-diene and norbornadiene with cyclodextrins. Organometallics 8, 2560-2563 (1989).

28. Colquhoun, H. M., Lewis, D. F., Stoddart, J. F. \& Williams, D. J. Crown ethers as second-sphere ligands. The interactions of transition-metal ammines with 18-crown-6 and dibenzo-18-crown-6. J. Chem. Soc., Dalton Trans. 607-613 (1983).

29. Sun, Q. -F. et al. Self-assembled $\mathrm{M}_{24} \mathrm{~L}_{48}$ polyhedra and their sharp structural switch upon subtle ligand variation. Science 328, 1144-1147 (2010).

30. Bunzen, J. et al. Self-assembly of $\mathrm{M}_{24} \mathrm{~L}_{48}$ polyhedra based on empirical prediction. Angew. Chem. Int. Ed. 51, 3161-3163 (2012).

31. Hill, J. P. et al. Self-assembled hexa-peri-hexabenzocoronene graphitic nanotube. Science 304, 1481-1483 (2004).

32. Palmer, L. C. \& Stupp, S. I. Molecular self-assembly into one-dimensional nanostructures. Acc. Chem. Res. 41, 1674-1684 (2008).

33. Bong, D. T., Clark, T. D., Granja, J. R. \& Ghadiri, M. R. Self-assembling organic nanotubes. Angew. Chem. Int. Ed. 40, 988-1011 (2001).

34. Lawrence, D. S., Jiang, T. \& Levett, M. Self-assembling supramolecular complexes. Chem. Rev. 95, 2229-2260 (1995).

35. Desiraju, G. R. Supramolecular synthons in crystal engineering-a new organic synthesis. Angew. Chem. Int. Ed. Engl. 34, 2311-2327 (1995).

36. Brunsveld, L., Folmer, B. J. B., Meijer, E. W. \& Sijbesma, R. P. Supramolecular polymers. Chem. Rev. 101, 4071-4098 (2001).

37. MacDonald, J. C. \& Whitesides, G. M. Solid-state structures of hydrogenbonded tapes based on cyclic secondary diamides. Chem. Rev. 94, 2383-2420 (1994).

38. Vögtle, F. \& Müller, W. M. Complexes of $\gamma$-cyclodextrin with crown ethers, cryptands, coronates, and cryptates. Angew. Chem. Int. Ed. Engl. 18, 623-624 (1979).

39. Kamitori, S., Hirotsu, K. \& Higuchi, T. Crystal and molecular structures of double macrocyclic inclusion complexes composed of cyclodextrins, crown ethers, and cations. J. Am. Chem. Soc. 109, 2409-2414 (1987).

40. Mähler, J. \& Persson, I. A study of the hydration of the alkali metal ions in aqueous solution. Inorg. Chem. 51, 425-438 (2012).

41. Song, L. X., Bai, L., Xu, X. M., He, J. \& Pan, S. Z. Inclusion complexation, encapsulation interaction and inclusion number in cyclodextrin chemistry. Coord. Chem. Rev. 253, 1276-1284 (2009).

42. Fu, Y., Liu, L. \& Guo, Q. -X. A theoretical study on the inclusion complexation of cyclodextrins with inorganic cations and anions. J. Incl. Phenom. Macrocycl. Chem. 43, 223-229 (2002).

43. Smaldone, R. A. et al. Metal-organic frameworks from edible natural products. Angew. Chem. Int. Ed. 49, 8630-8634 (2010).

44. Klüfers, P., Piotrowski, H. \& Uhlendorf, J. Homoleptic cuprates(II) with multiply deprotonated $\alpha$-cyclodextrin ligands. Chem. Eur. J. 3, 601-608 (1997).

45. Klüfers, P. \& Schuhmacher, J. Sixteenfold deprotonated $\gamma$-cyclodextrin tori as anions in a hexadecanuclear lead(II) alkoxide. Angew. Chem. Int. Ed. Engl. 33, 1863-1865 (1994).

46. Norkus, E. Metal ion complexes with native cyclodextrins. An overview. J. Incl. Phenom. Macrocycl. Chem. 65, 237-248 (2009).

47. Geißelmann, A., Klüfers, P., Kropfgans, C., Mayer, P. \& Piotrowski, H. Carbohydrate-metal interactions shaped by supramolecular assembling. Angew. Chem. Int. Ed. 44, 924-927 (2005). 
48. Steiner, T. Hydrogen-bond distances to halide ions in organic and organometallic crystal structures: up-to-date database study. Acta Crystallogr. B 54, 456-463 (1998).

49. Taylor, R. \& Kennard, O. Crystallographic evidence for the existence of $\mathrm{C}-\mathrm{H} \cdots \mathrm{O}, \mathrm{C}-\mathrm{H} \cdots \mathrm{N}$ and $\mathrm{C}-\mathrm{H} \cdots \mathrm{Cl}$ hydrogen bonds. J. Am. Chem. Soc. 104, 5063-5070 (1982).

50. Aakeröy, C. B., Evans, T. A., Seddon, K. R. \& Pálinkó, I. The C - H - ․ Cl hydrogen bond: does it exist? New J. Chem. 23, 145-152 (1999).

51. Aullon, G., Bellamy, D., Orpen, A. G., Brammer, L. \& Eric, A. B. Metal-bound chlorine often accepts hydrogen bonds. Chem. Commun. 653-654 (1998).

52. Nelson, A. P., Farha, O. K., Mulfort, K. L. \& Hupp, J. T. Supercritical processing as a route to high internal surface areas and permanent microporosity in metal - organic framework materials. J. Am. Chem. Soc. 131, 458-460 (2009).

53. Farha, O. K. \& Hupp, J. T. Rational design, synthesis, purification, and activation of metal-organic framework materials. Acc. Chem. Res. 43, 1166-1175 (2010)

54. Gassensmith, J. J. et al. Strong and reversible binding of carbon dioxide in a green metal-organic framework. J. Am. Chem. Soc. 133, 15312-15315 (2011).

\section{Acknowledgements}

We thank Amy A. Sarjeant and Charlotte L. Stern for carrying out single-crystal and powder XRD analysis. Z.J.B., J.T.H., and O.K.F. gratefully acknowledge financial support from the Defense Threat Reduction Agency (grant Nos HDTRA1-09-1-0007 and

HDTRA1-1-10-0023). D.C. and A.C.F. acknowledge the National Science Foundation for Graduate Research Fellowships. J.L. acknowledges the Chinese Scholarship Council for providing financial support during her stay at Northwestern University. D.C. also acknowledges the International Institute of Nanotechnology for a Ryan Fellowship.

\section{Author contributions}

Z.L. conceived and designed the research, carried out most of experiments, analysed the data and composed the manuscript. Z.L., Z.Z. and J.I. performed single-crystal growth. M.F., G.L. and C.A.M. performed AFM studies. J.L. and Z.L. performed SEM, STEM, SAED and PXRD experiments and processed the data. J.T.H., O.K.F., Z.J.B. and J.L. performed gas adsorption studies and TGA analysis. M.F. performed ICP studies. Z.L., M.F., G.L. and D.C. performed the gold recovery experiments. D.C. made the movie and contributed to the preparation of this manuscript. A.C.F. contributed to the preparation of this manuscript. J.F.S. oversaw the preparation of the manuscript. All authors discussed and commented on the manuscript.

\section{Additional information}

Accession code: The single-crystal diffraction data for all six complexes were deposited in the Cambridge Crystallographic Data Centre (CCDC) and the deposition numbers are CCDC $918412-918417$.

Supplementary Information accompanies this paper at http://www.nature.com/ naturecommunications

Competing financial interests: The authors declare no competing financial interests.

Reprints and permission information is available online at http://npg.nature.com/ reprintsandpermissions/

How to cite this article: Liu, Z. et al. Selective isolation of gold facilitated by secondsphere coordination with $\alpha$-cyclodextrin. Nat. Commun. 4:1855 doi: 10.1038/ ncomms2891 (2013).

(c) $(1)($ This work is licensed under a Creative Commons Attribution-
NonCommercial-NoDerivs 3.0 Unported License. To view a copy of this license, visit http://creativecommons.org/licenses/by-nc-nd/3.0/ 